\title{
Toxicity of intraperitoneal bisulfite
}

\begin{abstract}
Studies were carried out in animals to investigate the toxicity of intraperitoneal bisulfite. The $L D_{50}$ (dose lethal to 50 per cent of the animals) for a single intraperitoneal injection of $\mathrm{NaHSO}_{3}$ was calculated in the mouse, rat, rabbit, and dog. Studies indicated that the $L D_{s a}$ dose was increased by dilution of the bisulfite. When sodium bisulfite was infused at a rate of $80 \mathrm{mg}$. of $\mathrm{NaHSO}_{3}$ per kilogram per hour in the portal vein of dogs having bilateral ureteral ligations, bisulfite did not accumulate in the serum. Autoclaving dialysis fluid substantially reduced its bisulfite concentration. These studies suggest that $\mathrm{NaHSO}_{3}$ in amounts usually added to dialysis solutions is unlikely to cause toxicity in patients undergoing peritoneal dialysis.
\end{abstract}

James W. Wilkins, Jr., M.D.,* James A. Greene, Jr., M.D., and John M. Weller, M.D. Ann Arbor, Mich.

Department of Internal Medicine, The University of Michigan

Sodium bisulfite $\left(\mathrm{NaHSO}_{3}\right)$ is added to parenteral solutions as an antioxidant. The peritoneal dialysis solutions used in our hospital contained 0.01 per cent $\mathrm{NaHSO}_{3}$ in the 1.5 per cent glucose solution and 0.05 per cent $\mathrm{NaHSO}_{3}$ in the 7 per cent glucose solution. A patient given $48 \mathrm{~L}$. of dialysate daily, 12 of which are the 7 per cent glucose solution, would be exposed to $9,600 \mathrm{mg}$. of $\mathrm{NaHSO}_{3}$. The possibility of excessive administration of $\mathrm{NaHSO}_{3}$ by this route warranted further investigation. The following studies in animals were carried out to determine the toxicity of peritoneal dialysis solutions containing $\mathrm{NaHSO}_{3}$.

\section{Materials and methods}

Experiment I-Single-dose intraperitoneal $\mathrm{LD}_{50}$ values of $\mathrm{NaHSO}_{3}$. The ani-

Supported by grants from the Michigan Memorial Phoenix Project and the Michigan Kidney Foundation.

Received for publication Nov. 25, 1967.

Accepted for publication Jan. 12, 1968.

* Predoctoral trainee, Public Health Service Grant No. HTS HE 546505. mals used were male Swiss-Webster white mice weighing 19 to 25 grams; male Sprague-Dawley white rats weighing 235 to 310 grams; male New Zealand white rabbits weighing 1.1 to 1.9 kilograms; and male and female mongrel dogs weighing 7.8 to 15.8 kilograms. Animals were fasted 24 hours prior to and during the day of injection. Four animals of each species were tested at each of four dosage levels. Mice were given $300 \mathrm{mg}$. per kilogram of body weight* of a 1.25 per cent $\mathrm{NaHSO}_{3}$ solution which was prepared immediately prior to injection in normal saline from which dissolved gases had been evacuated. Subsequent dose levels were each increased by 50 per cent. The solutions given to the rats, rabbits, and dogs contained 25 per cent $\mathrm{NaHSO}_{3}$ similarly prepared. Rats were given the same dose as mice. Rabbits were given $133 \mathrm{mg}$. of $\mathrm{NaHSO}_{3}$ per kilogram and this dose level was increased 50 per cent each time. Dogs were given

\footnotetext{
*All doses throughout the rest of this paper are expressed in relation to body weight.
} 
$174 \mathrm{mg}$. of $\mathrm{NaHSO}_{3}$ per kilogram with each subsequent dose increased 33 per cent. Animals were observed for 72 hours following injection. $\mathrm{LD}_{50}$ (dose lethal to 50 per cent of the animals ) values were calculated using the methods of Weil. ${ }^{5}$

Experiment II-Single-dose intraperitoneal $L D_{s 0}$ values and the effect of the $\mathrm{NaHSO}_{3}$ concentration. To investigate the effect of the $\mathrm{NaHSO}_{3}$ concentration on the single-dose intraperitoneal $\mathrm{LD}_{50}$, male Sprague-Dawley rats weighing 350 to 400 grams were used. Two concentrations of $\mathrm{NaHSO}_{3}$ solution ( 5 and 1.25 per cent) were used to compare with the similarly prepared 25 per cent solution in Experiment I. Four animals were injected with 500 mg. of $\mathrm{NaHSO}_{3}$ per kilogram and this dose level was increased by 33 per cent each of three additional doses. Animals were observed for 72 hours and $L_{50}$ values were calculated.

Experiment III-Measurement of bisulfite in biological fluids. A method was devised to measure bisulfite in various biological solutions. ${ }^{6}$ The solution containing bisulfite was placed in a Conway microdiffusion unit and acidified. The liberated $\mathrm{SO}_{2}$ gas was trapped as $\mathrm{H}_{2} \mathrm{SO}_{3}$ in solution, oxidized by hydrogen peroxide to nonvolatile $\mathrm{H}_{2} \mathrm{SO}_{4}$, then titrated with weak $\mathrm{NaOH}$. This method was used in following serum bisulfite levels in Experiment IV and in determining bisulfite concentrations in dialysis solutions following autoclaving of six different bottles of 7 per cent glucose dialysis fluid and six different bottles of 1.5 per cent glucose dialysis fluid. All determinations were run in triplicate.

Experiment IV-Serum levels of bisulfite during continuous intravenous administration of solutions containing $\mathrm{NaHSO}$. Three mongrel dogs weighing 15 to 22 kilograms were anesthetized with $30 \mathrm{mg}$. of pentobarbital per kilogram intravenously, and their ureters were ligated by an abdominal approach. The splenic vein was cut free, a polyethylene catheter inserted, and freshly prepared solutions of $\mathrm{NaHSO}_{3}$ in normal saline were infused at a rate of $160 \mathrm{mg}$. per kilogram per hour for three hours. Immediately following this an infusion of $80 \mathrm{mg}$. of $\mathrm{NaHSO}_{3}$ per kilogram per hour was carried out for an additional three hours. Blood samples for bisulfite analysis were drawn hourly from a catheter in the femoral artery.

\section{Results}

Experiment 1. The single intraperitoneal dose $\mathrm{LD}_{50}$ values were determined to be $675,498,300$, and $244 \mathrm{mg}$. of $\mathrm{NaHSO}_{3}$ per kilogram for the mouse, rat, rabbit, and dog, respectively (Table $I$ ). In all cases of death due to bisulfite, animals died within 45 minutes of injection. The manner of death was best observed in the dog. The animals were extremely irritable and had clonic convulsions followed by respiratory instability with periods of apnea and cyanosis. Terminally, there was evidence of cardiovascular collapse associated with prolonged apnea.

Experiment II. The $\mathrm{LD}_{50}$ in the rat for a single intraperitoneal dose was found to be dependent upon the concentration of $\mathrm{NaHSO}_{3}$ in the injected solution. The $\mathrm{LD}_{50}$ values were 498,650 , and $740 \mathrm{mg}$. of $\mathrm{NaHSO}_{3}$ per kilogram with the 25, 5, and 1.25 per cent $\mathrm{NaHSO}_{3}$ solutions, respectively (Table I).

Experiment III. Dialysis fluid bisulfite concentrations determined following autoclaving revealed a marked loss in the quantity of bisulfite in solution. The 7 per cent glucose solutions to which $500 \mathrm{mg}$. of $\mathrm{NaHSO}_{3}$ per liter were added prior to autoclaving were found to contain $47 \mathrm{mg}$. of $\mathrm{NaHSO}_{3}$ per liter ( \pm S.E.M. of $5 \mathrm{mg}$. per liter) following autoclaving. The solutions of 1.5 per cent glucose to which $100 \mathrm{mg}$. of $\mathrm{NaHSO}_{3}$ per liter had been added contained less than $25 \mathrm{mg}$. of $\mathrm{NaHSO}_{3}$ per liter following autoclaving. (Reliability of this method for determining concentrations of $\mathrm{NaHSO}_{3}$ less than $25 \mathrm{mg}$. per liter was not evaluated.)

Experiment $I V$. The serum concentration of $\mathrm{NaHSO}_{3}$ in the dog was determined during continuous splenic vein infusion of 
Table I. Single-dose intraperitoneal $L D_{50}$ studies of sodium bisulfite

\begin{tabular}{|c|c|c|c|c|c|c|c|c|c|c|c|c|}
\hline & \multirow{2}{*}{\multicolumn{2}{|c|}{$\begin{array}{c}\text { Mouse } \\
1.25 \mathrm{Gm} . \\
\mathrm{NaHSO} \\
\text { per } 100 \mathrm{ml} \text {. } \\
\text { solution }\end{array}$}} & \multicolumn{6}{|c|}{ Rat } & \multirow{2}{*}{\multicolumn{2}{|c|}{$\begin{array}{c}\text { Rabbit } \\
25 \mathrm{Gm} . \\
\mathrm{NaHSO}_{3} \\
\text { per } 100 \mathrm{ml} . \\
\text { solution }\end{array}$}} & \multirow{2}{*}{\multicolumn{2}{|c|}{$\begin{array}{c}\text { Dog } \\
25 \mathrm{Gm} . \\
\mathrm{NaHSO} \\
\text { per } 100 \mathrm{ml} . \\
\text { solution }\end{array}$}} \\
\hline & & & \multicolumn{2}{|c|}{$\begin{array}{c}25 \mathrm{Gm} . \\
\mathrm{NaHSO} \\
\text { per } 100 \mathrm{ml} \text {. } \\
\text { solution }\end{array}$} & \multicolumn{2}{|c|}{$\begin{array}{c}5 \mathrm{Gm} . \\
\mathrm{NaHSO}_{3} \\
\text { per } 100 \mathrm{ml} . \\
\text { solution }\end{array}$} & \multicolumn{2}{|c|}{$\begin{array}{c}1.25 \mathrm{Gm} . \\
\mathrm{NaHSO}_{3} \\
\text { per } 100 \mathrm{ml} . \\
\text { solution }\end{array}$} & & & & \\
\hline & $\begin{array}{c}\text { Dose } \\
(m g . / \\
\text { Kg. })\end{array}$ & Deaths & $\begin{array}{l}\text { Dose } \\
\text { (mg.) } \\
\text { Kg.) }\end{array}$ & Deaths & $\begin{array}{c}\text { Dose } \\
\text { (mg./ } \\
\text { Kg.) }\end{array}$ & Deaths & \begin{tabular}{|c|} 
Dose \\
$(m g . /$ \\
Kg. $)$
\end{tabular} & Deaths & $\begin{array}{c}\text { Dose } \\
(m g .) \\
\text { Kg.) }\end{array}$ & Deaths & $\begin{array}{l}\text { Dose } \\
\text { (mg./ } \\
\text { Kg.) }\end{array}$ & Deaths \\
\hline & 300 & $0 / 4$ & 300 & $0 / 4$ & 500 & $0 / 4$ & 500 & $0 / 4$ & 133 & $0 / 4$ & 174 & $0 / 4$ \\
\hline & 450 & $0 / 4$ & 450 & $1 / 4$ & 654 & $4 / 4$ & 654 & $0 / 4$ & 200 & $2 / 4$ & 230 & $1 / 4$ \\
\hline & 675 & $2 / 4$ & 675 & $4 / 4$ & 852 & $2 / 4$ & 852 & $3 / 4$ & 300 & $1 / 4$ & 300 & $4 / 4$ \\
\hline & 1,012 & $4 / 4$ & 1,012 & $4 / 4$ & 1,125 & $4 / 4$ & 1,125 & $4 / 4$ & 450 & $3 / 4$ & 393 & $4 / 4$ \\
\hline $\begin{array}{l}\mathrm{LD}_{50}: \\
\quad(\mathrm{mg} . / \mathrm{Kg} .)\end{array}$ & \multicolumn{2}{|c|}{675} & \multicolumn{2}{|c|}{498} & \multicolumn{2}{|c|}{650} & \multicolumn{2}{|c|}{740} & \multicolumn{2}{|c|}{300} & \multicolumn{2}{|c|}{244} \\
\hline $\begin{array}{l}95 \% \text { confi- } \\
\text { dence range } \\
\text { of } \mathrm{LD}_{50}: \\
\text { ( } \mathrm{mg} . / \mathrm{Kg} .)\end{array}$ & \multicolumn{2}{|c|}{534 to 853} & \multicolumn{2}{|c|}{406 to 610} & \multicolumn{2}{|c|}{558 to 756} & \multicolumn{2}{|c|}{650 to 845} & \multicolumn{2}{|c|}{183 to 491} & \multicolumn{2}{|c|}{213 to 279} \\
\hline
\end{tabular}

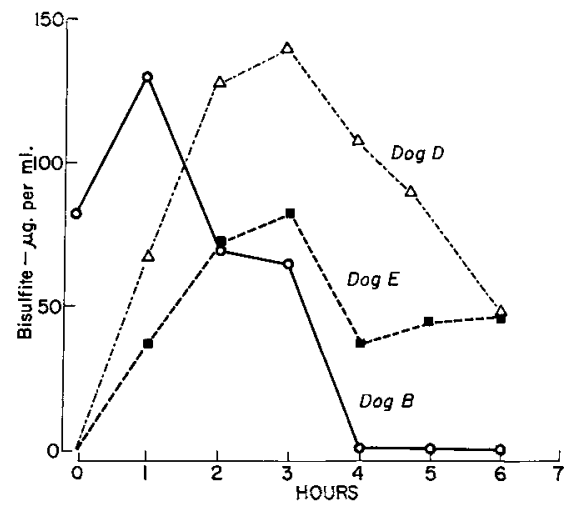

Fig. 1. The serum level of bisulfite (micrograms per milliliter) of three dogs during splenic vein infusion of $\mathrm{NaHSO}_{3}$ is plotted against the hours of infusion. The infusion rate was $160 \mathrm{mg}$. of $\mathrm{NaHSO}_{3}$ per kilogram per hour for the first three hours, then was reduced to $80 \mathrm{mg}$. of $\mathrm{NaHSO}_{3}$ per kilogram per hour for the subsequent three hours. Dog B received a loading infusion of 240 mg. of $\mathrm{NaHSO}_{3}$ per kilogram per hour for two hours prior to the determination of the serum level at time zero.

$\mathrm{NaHSO}_{3}$ solutions. Following three hours of infusion at a rate of $160 \mathrm{mg}$. per kilogram per hour, levels of 50 to $140 \mu \mathrm{g}$ $\mathrm{NaHSO}_{3}$ per milliliter of serum were recorded. In all three animals, a prompt fall in the serum concentration of bisulfite followed reduction in the infusion rate from 160 to $80 \mathrm{mg}$. of $\mathrm{NaHSO}_{3}$ per kilogram per hour. In one animal the serum bisulfite level after one hour fell to less than $25 \mu \mathrm{g}$ per milliliter and in the other two to between 25 and $50 \mu \mathrm{g}$ per milliliter (Fig. 1).

\section{Discussion}

Little is known about the acute toxicity of $\mathrm{NaHSO}_{3}$, and even less about chronic toxicity. Hoppe and Goble ${ }^{3}$ found the single-dose intravenous $\mathrm{LD}_{50}$ of $\mathrm{NaHSO}_{3}$ to be $130 \mathrm{mg}$. per kilogram for the mouse, $115 \mathrm{mg}$. per kilogram for the rat, $95 \mathrm{mg}$. per kilogram for the hamster, and $65 \mathrm{mg}$. per kilogram for the rabbit. The $\mathrm{LD}_{\overline{5}}$ per kilogram decreases as animals increase in size. The toxicity of long-term exposure to bisulfite also was studied by Hoppe and Goble $^{3}$ in the rabbit. The intravenous administration of two thirds of the intravenous $\mathrm{LD}_{50}$ dose, given every eight hours, five days a week, for three weeks, caused no deaths or pathophysiologic changes.

Reiss and Gerstl ${ }^{4}$ investigated the intraperitoneal toxicity of $\mathrm{NaHSO}_{3}$ in mice and reported that $0.18 \mathrm{mmole}$ (18.54 $\mathrm{mg}$.) or more given intraperitoneally caused death 
within a few minutes. Two of five mice died after injection of 0.12 mmole ( 12.36 mg.). Reiss and Gerstl found that bisulfite in toxic doses had an immediate effect on the central nervous system as indicated by clonic convulsions, and on the cardiovascular center with rapid fall of blood pressure.

Bhaghat and Lockett ${ }^{1}$ administered $\mathrm{NaHSO}_{3}$ intraperitoneally to rats and found that a single injection of an isotonic solution of bisulfite equal to 3 per cent of body weight ( $585 \mathrm{mg}$. per kilogram) killed half of the animals. Toxic doses caused restlessness, cyanosis, prostration, and finally cardiovascular collapse with death within 35 minutes. Eighty to 90 per cent of a sublethal dose of $\mathrm{NaHSO}_{3}$ could be accounted for as sulfate in the urine within four hours.

The toxicity of peritoneal dialysis solutions containing $\mathrm{NaHSO}_{3}$ has been investigated by Halaby and Mattocks. ${ }^{2}$ They administered 7 per cent glucose dialysis solution containing $\mathrm{S}^{35}$-labeled bisulfite in single or repeated intraperitoneal doses to rabbits and demonstrated accumulation of $\mathrm{S}^{35}$ in the plasma. Following death of several animals they concluded "that the use of $500 \mathrm{mg}$. per liter of $\mathrm{NaHSO}_{3}$ in peritoneal dialysis fluids is dangerous and should be discontinued." To implicate $\mathrm{NaHSO}_{3}$ toxicity in these deaths is unwarranted since: (1) The total dose that the rabbits received varied from 16 to $48 \mathrm{mg}$. per kilogram, which is less than the intravenous $\mathrm{LD}_{50}(65 \mathrm{mg}$.) reported by Hoppe and Goble $^{3}$ and considerably less than the intraperitoneal $\operatorname{LD}_{50} \quad(300$ mg.) reported here. (2) In the studies of Halaby and Mattocks ${ }^{2}$ animals died from 337 minutes to 30 hours following injection, much longer than the period of time for bisulfite to cause death reported by others and confirmed in this study. ${ }^{1,3,4}$ (3) The $S_{35}$-labeled material that Halaby and Mattocks ${ }^{2}$ found accumulating in the serum of rabbits was not necessarily bisulfite. They did not distinguish that radioactivity due to bi- sulfite from that due to sulfate or other metabolites. Indeed, if one attempts to measure bisulfite in protein-free supernatants prepared with 15 per cent trichloracetic acid, there is poor and inconsistent bisulfite recovery. ${ }^{6}$ Much of the $S_{35}$ found in serum is probably in the form of sulfate, as there is rapid and relatively unlimited ability to metabolize bisulfite to sulfate. ${ }^{1,3}$

As shown in Experiment II, when more dilute solutions are used, the bisulfite $\mathrm{LD}_{50}$ rises in rats. This indicates that with dilution a smaller amount of bisulfite moves across the peritoneum per unit time, therefore a greater total amount is required. The bisulfite concentrations used in these rats are several times greater than that present in the peritoneal dialysis fluid used in patients.

Previous investigators have reported that bisulfite given intravenously in sublethal doses over long periods of time is nontoxic. ${ }^{3}$ There is rapid conversion of bisulfite to nontoxic substances. ${ }^{1}$ Peritoneal dialysis is a chronic intermittent type of treatment. In Experiment IV, bisulfite was infused directly into the splenic vein to eliminate uncertainty regarding the rate of absorption of bisulfite from the peritoneal cavity. The ureters were ligated so that renal excretion would play a small role in protecting from bisulfite toxicity, since peritoneal dialysis is used in patients with greatly reduced renal function. Infusion of $160 \mathrm{mg}$. of sodium bisulfite per kilogram per hour resulted in a constant, albeit small, increase in bisulfite concentration in the serum. This rising level of bisulfite was reversed by decreasing the infusion rate to $80 \mathrm{mg}$. per kilogram per hour, indicating that in the dog the metabolism of sodium bisulfite to sulfate occurs at a rate of at least $80 \mathrm{mg}$. per kilogram of body weight per hour, at least four times the maximal conceivable exposure in a human undergoing chronic intermittent peritoneal dialysis (i.e., in a 50 kilogram patient receiving $2 \mathrm{~L}$. of the 7 per cent glucose solution per hour, or $20 \mathrm{mg}$. of $\mathrm{NaHSO}_{3}$ per 
kilogram). Moreover, the rate of absorption and, therefore, the likelihood of toxicity in a man would be minimized by the more dilute bisulfite solutions used in peritoneal dialysis.

Peritoneal dialysis solutions are usually sterilized by autoclaving. The amount of bisulfite remaining following autoclaving of the dialysis fluid is even less than 25 per cent of the formulated amount. On the basis of these studies, it seems unlikely, therefore, that death due to bisulfite can result in man from chronic intermittent peritoneal dialysis.

\section{Conclusions}

Studies in animals on the toxicity of intraperitoneally administered bisulfite and determination of the rate of metabolism of the bisulfite given intravenously, coupled with the finding that the amount of bisulfite in peritoneal dialysis solutions is greatly reduced by autoclaving, suggest that sodium bisulfite added to peritoneal dialysis solutions as an antioxidant is not likely to result in toxicity in patients.

\section{References}

1. Bhaghat, B., and Lockett, M. F.: The absorption and elimination of metabisulfite and thiosulphate by rats, J. Pharm. \& Pharmacol. 12: 690-694, 1960.

2. Halaby, S. F., and Mattocks, A. M.: Absorption of sodium bisulfite from peritoneal dialysis solutions, J. Pharm. Sc. 54: 52-55, 1965.

3. Hoppe, J. O., and Goble, F. C.: The intravenous toxicity of sodium bisulfite, J. Pharmacol. \& Exper. Therap. 101:101-106, 1951.

4. Reiss, F., and Gerstl, B.: The systemic and local effects of thyoglycolic acid and bisulfite compounds, Exper. Med. \& Surg. 4:338-347, 1946.

5. Weil, C. S.: Tables for convenient calculation of medium-effective dose $\left(\mathrm{LD}_{50}\right.$ or $\left.\mathrm{ED}_{50}\right)$ and instructions in their use, Biometrics 8:249-263, 1952.

6. Wilkins, J. W., Jr., and Rivecca, J. N.: Measurement of bisulfite in biologic solutions. To be published. 